\title{
The effect of Helicobacter pylori eradication on prognosis of postoperative early gastric cancer: a multicenter study
}

Liang Wang ${ }^{1}$, Jinfeng Wang ${ }^{2}$, Sha Li ${ }^{2}$, Fei Bai ${ }^{2}$, Hailong Xie ${ }^{3}$, Hanguo Shan ${ }^{3}$, Zhuo Liư ${ }^{4}$, Tiexiang Ma ${ }^{4}$, Xiayu Tang ${ }^{5}$, Haibing Tang ${ }^{6}$, Ang Qin ${ }^{2}$, Sanlin Lei ${ }^{7^{*}}$ and Chaohui Zuo ${ }^{1,2^{*}}$ (D)

\begin{abstract}
Objective: To investigate the effect of Helicobacter pylori (H. pylori) eradication on the prognosis of postoperative early gastric cancer (EGC).

Methods: This is a retrospective study based on data from 6 hospitals. We identified 429 patients with EGC who underwent curative gastrectomy from January 2010 to December 2016. All of the patients were tested for H. pylori. Patients were divided into two groups, the successful H. pylori eradication group (group A, 268 patients) and the nonH. pylori eradication group (group B, 161 patients), for calculating the disease-free survival (DFS) and overall survival (OS) of each group.
\end{abstract}

Result: Positive node metastasis (hazard ratio (HR), 3.13; 95\% confidence interval (Cl), 1.84-5.32; $P<0.001$ ), undifferentiated type ( $\mathrm{HR}, 2.54 ; 95 \% \mathrm{Cl}, 1.51-4.28 ; P<0.001)$, and non-H. pylori eradication $(\mathrm{HR}, 1.73 ; 95 \% \mathrm{Cl}, 1.08-2.77 ; P=0.023)$ were statistically significantly independent risk factors of recurrence. Patient's age $\geq 60$ years old $(\mathrm{HR}, 3.32 ; 95 \% \mathrm{Cl}$, 2.00-5.53; $P<0.001)$, positive node metastasis ( $\mathrm{HR}, 3.71 ; 95 \% \mathrm{Cl}, 2.25-6.12 ; P<0.001)$, undifferentiated type (HR, 3.06; $95 \% \mathrm{Cl}, 1.79-5.23 ; P<0.001)$, and non-H. pylori eradication ( $\mathrm{HR}, 1.83 ; 95 \% \mathrm{Cl}, 1.11-3.02 ; P=0.018)$ were statistically significantly independent risk factors of overall survival.

Conclusion: H. pylori eradication treatment could prevent the recurrence of postoperative EGC to prolong the overall survival of patients with EGC.

Keywords: Early gastric cancer (EGC), Helicobacter pylori (H. pylori), Prognosis, Risk factors

\footnotetext{
*Correspondence: leisanlin@csu.edu.cn; zuochaohui@vip.sina.com

${ }^{2}$ Department of Gastroduodenal and Pancreatic Surgery, Translational

Medicine Research Center of Liver Cancer, Laboratory of Digestive

Oncology, Hunan Cancer Hospital (Hunan Cancer Institute) \&

the Affiliated Cancer Hospital of Xiangya School of Medicine, Hunan

Province Key Laboratory of Virology (Tumor Immunity), Central South

University, 283 Tongzipo Road, Changsha, Hunan Province 410013,

People's Republic of China

${ }^{7}$ Department of General Surgery, The Second Xiangya Hospital of Central

South University, 139 Renmin Middle Road, Changsha, Hunan Province

410011, People's Republic of China

Full list of author information is available at the end of the article
}

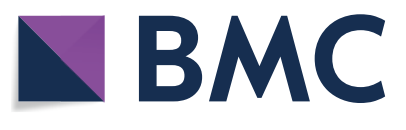

2021. Open Access This article is licensed under a Creative Commons Attribution 4.0 International License, which permits use, sharing, adaptation, distribution and reproduction in any medium or format, as long as you give appropriate credit to the original author(s) and the source, provide a link to the Creative Commons licence, and indicate if changes were made. The images or other third party material in this article are included in the article's Creative Commons licence, unless indicated otherwise in a credit line to the material. If material is not included in the article's Creative Commons licence and your intended use is not permitted by statutory regulation or exceeds the permitted use, you will need to obtain permission directly from the copyright holder. To view a copy of this licence, visit http://creativecommons.org/licenses/by/4.0/. The Creative Commons Public Domain Dedication waiver (http://creativeco mmons.org/publicdomain/zero/1.0/) applies to the data made available in this article, unless otherwise stated in a credit line to the data. 


\section{Introduction}

Gastric cancer (GC) is the fifth most common cancer and the third deadly cancer, with more than 780,000 annual deaths all over the world in 2018 [1]. The highest age-standardized incidence is found in Eastern Asian populations, and the lowest in Northern Africa populations. The age-standardized incidence in South Korea is 32.1 and 13.2 per 100,000 individuals in men and women, respectively. Helicobacter pylori (H. pylori) plays a vital role in the occurrence and development of GC. Strong epidemiological and clinical evidence has shown that $H$. pylori infection is positively correlated with active chronic gastritis, peptic ulcers, atrophic gastritis, intestinal metaplasia, and GC [2, 3]. People who were infected with $H$. pylori have a more than threefold increase in risk of GC [4]. The 5-year survival rate for GC in 2005-2009 was 54-58\% in Japan and South Korea [5], while the 5-year survival rate of EGC is more than $90 \%$. A previous meta-analysis has suggested that $H$. pylori eradication reduces the risk of GC [6]. However, the role of $H$. pylori eradication on the effect of prognosis on EGC has not been thoroughly examined. Recurrence is still a key factor affecting the survival of patients with EGC. This study aims to investigate the effect of $H$. pylori eradication on the postoperative prognosis of patients with EGC.

\section{Methods}

\section{Study population}

We identified 429 patients with EGC who underwent curative gastrectomy for GC from January 2010 to December 2016 from six hospitals (253 patients from Hunan Province Cancer Hospital, 109 patients from the Second Xiangya Hospital of Central South University, 23 patients from the Second Affiliated Hospital of University of South China, 19 patients from the Central Hospital of Xiangtan City, 17 patients from Yongzhou Central Hospital, and 8 patients from People Hospital of Qiyang County). All patients were tested for $H$. pylori by a carbon-14 (C-14) breath test. All cases were pathologically diagnosed as EGC and were consulted by the Multiple Disciplinary Team (MDT) in each center. Curative gastrectomy was performed on all patients who did not undergo or did not wish to undergo neoadjuvant chemotherapy. For a long time, there is no international consensus on whether patients with GC can benefit from H. pylori eradication treatment after surgery. In clinical practice, whether or not to treat with $H$. pylori eradication is mainly up to the patient's choice. The exclusion criteria are negative $H$. pylori and $H$. pylori eradication failure. Finally, a total of 429 patients included were divided into two groups, the successful $H$. pylori eradication group (group A) and the non-H. pylori eradication group (group B). Group A received standard triple therapy (esomeprazole $20 \mathrm{mg}$ bis in die (bid), amoxicillin $1 \mathrm{~g}$ bid, and clarithromycin $0.5 \mathrm{~g}$ bid) orally for 7 days. $H$. pylori were identified by a C-14 breath test 1 month after treatment.

\section{Definition}

EGC is defined as gastric adenocarcinoma limited to the mucosa or submucosa, no matter whether it has lymph node metastasis or not. According to the Japanese Gastric Cancer Association principles [7], the stomach is anatomically divided into three portions, the lower part, the middle part, and the upper part. The tumor size is measured by the maximum diameter of the tumor. The macroscopic classification of GC was divided into three types, elevated type (types $0-\mathrm{I}, 0-\mathrm{I}+\mathrm{II}$ a, $0-\mathrm{II}$ a, $0-\mathrm{II}$ a + II b, 0 -II a + II c), flat type (type 0-II b), and depressed type (types 0-II c, 0-III, 0-II c + II a, and 0-III+II a). According to WHO criteria, the histological classification of GC was classified into two different types, undifferentiated type (including mucinous adenocarcinoma, poorly differentiated tubular adenocarcinoma, and signet-ring cell carcinoma) and differentiated type (including well and moderately differentiated tubular adenocarcinoma and papillary adenocarcinoma).

\section{Follow-up}

Patients with EGC were followed up regularly after the radical gastrectomy. The last follow-up date was July 30, 2020. The patients were followed up every 6 months for the first 3 years after surgery and then once a year until death or loss to follow-up. The follow-up information, including the time of patient relapse or death, was collected from hospital information systems, patients, or patients' family members. Overall survival (OS) was calculated from the date of pathological diagnosis to death or the last date of follow-up. Disease-free survival (DFS) was calculated from the date of pathological diagnosis to recurrence or the last date of follow-up.

\section{Statistical analysis}

The data were statistically processed using SPSS22.0 statistical software. Student $t$-test was used for comparing numerical data and the Pearson chi-square test for comparing categorical data. Data are shown as the mean \pm standard deviation. Univariate and multivariate analysis were performed by Cox proportional hazards regression model. The survival curve was traced using the Kaplan-Meier method, the difference between curves was tested using the log-rank test. A 2-tailed $P$ value less than 0.05 was considered statistically significant difference. 
Table 1 Baseline characteristics of patients with EGC

\begin{tabular}{|c|c|c|c|c|}
\hline & Total & Group A & Group B & Pvalue \\
\hline Patient number & 429 & 268 & 161 & \\
\hline Age (mean $\pm S D$ ), years & $55.94 \pm 9.50$ & $55.90 \pm 9.49$ & $56.01 \pm 9.53$ & 0.908 \\
\hline$\geq 60$ & $157(36.6 \%)$ & $99(36.9 \%)$ & $58(36.0 \%)$ & 0.849 \\
\hline$<60$ & $272(63.4 \%)$ & $169(63.1 \%)$ & $103(64.0 \%)$ & \\
\hline Gender & & & & 0.667 \\
\hline Male & $272(63.4 \%)$ & $172(64.2 \%)$ & $100(62.1 \%)$ & \\
\hline Female & $157(36.6 \%)$ & $96(35.8 \%)$ & $61(38.9 \%)$ & \\
\hline Tumor location & & & & 0.990 \\
\hline Upper & $58(13.6 \%)$ & $36(13.4 \%)$ & $22(13.7 \%)$ & \\
\hline Middle & $140(32.6 \%)$ & $87(32.5 \%)$ & $53(32.9 \%)$ & \\
\hline Lower & $231(53.8 \%)$ & $145(54.1 \%)$ & $86(53.4 \%)$ & \\
\hline Tumor size, mean $\pm S D, m m$ & $24.5 \pm 10.6$ & $23.9 \pm 10.5$ & $25.3 \pm 10.7$ & 0.176 \\
\hline$\geq 20$ & $267(62.2 \%)$ & $159(59.3 \%)$ & $108(67.1 \%)$ & 0.109 \\
\hline$<20$ & $162(37.8 \%)$ & $109(40.7 \%)$ & $53(32.9 \%)$ & \\
\hline Depth of invasion & & & & 0.525 \\
\hline Mucosa & $219(51.0 \%)$ & $140(52.2 \%)$ & 79 (49.1\%) & \\
\hline Submucosa & $210(49.0 \%)$ & $128(47.8 \%)$ & $82(50.9 \%)$ & \\
\hline Macroscopic type & & & & 0.510 \\
\hline Depressed & $229(53.4 \%)$ & $147(54.9 \%)$ & 82 (50.9\%) & \\
\hline Flat & $136(31.7 \%)$ & $85(31.7 \%)$ & $51(31.7 \%)$ & \\
\hline Elevate & $64(14.9 \%)$ & $36(13.4 \%)$ & $28(17.4 \%)$ & \\
\hline Node metastasis & & & & 0.924 \\
\hline Positive & $71(16.6 \%)$ & $44(16.4 \%)$ & $27(16.8 \%)$ & \\
\hline Negative & $388(83.4 \%)$ & $224(83.6 \%)$ & $134(83.2 \%)$ & \\
\hline Histology & & & & 0.404 \\
\hline Undifferentiated type & $218(50.8 \%)$ & $132(49.3 \%)$ & $86(53.4 \%)$ & \\
\hline Differentiated type & $211(49.2 \%)$ & $136(50.7 \%)$ & 75 (46.6\%) & \\
\hline
\end{tabular}

The data are expressed as the number, with the percentage in parentheses

SD Standard deviation

\section{Result}

\section{Patients' characteristic}

The baseline characteristics of these 429 patients are shown in Table 1. Group A and group B have no significant differences in sex ratio, age, tumor size, the depth of invasion, histological classification, and macroscopic classification. The average age of patients was $56.01 \pm 9.53$ years. The percentage of female patients $(36.6 \%, 157 / 429)$ was lower than male patients $(63.4 \%$, 272/429) among patients with EGC. The average size of the tumor was $24.5 \pm 10.6 \mathrm{~mm}$. The most common tumor location was the lower third of the stomach $(53.8 \%, 231 / 429)$, followed by the middle (32.6\%, $140 / 429)$ and upper $(13.5 \%, 58 / 429)$ parts of the stomach. The most common gross appearance was the depressed type $(53.4 \%, 229 / 429)$, followed by the flat type $(31.7 \%$, $136 / 429)$ and elevated type $(14.9 \%, 64 / 429)$. The percentage of differentiated type $(49.2 \%, 211 / 429)$ is very similar to undifferentiated type $(50.8 \%, 218 / 429)$. Totally, 210 (49.0\%) patients had submucosal invasion and 41 patients (16.6\%) had lymph node metastasis.

\section{Risk factors of recurrence among postoperative with EGC}

We conducted univariate Cox analysis to identify the prognostic significance of clinicopathological factors for DFS. Positive node metastasis (HR, 3.17; 95\% CI, $1.92-5.21 ; P<0.001)$, submucosal invasion (HR, 1.84; 95\% CI, $1.15-2.94 ; P=0.011)$, non- $H$. pylori eradication (HR, 1.64; 95\% CI, 1.03-2.61; $P=0.037$ ), and undifferentiated type (HR, 2.90; 95\% CI, 1.75-4.79; $P<0.001)$ were found to be risk factors for recurrence in patients with EGC. Further adjustment of covariate factors using multivariate Cox analysis identified positive node metastasis (HR, 3.13; 95\% CI, 1.84-5.32; $P<0.001$ ), undifferentiated type (HR, 2.54; 95\% CI, 1.51-4.28; $P<0.001)$, and non-H. pylori eradication (HR, 1.73; 95\% CI, 1.08-2.77; 
Table 2 Predictive factors of recurrence of postoperative EGC

\begin{tabular}{|c|c|c|c|c|c|c|}
\hline & \multicolumn{3}{|c|}{ Univariate } & \multicolumn{3}{|c|}{ Multivariate } \\
\hline & HR & $95 \% \mathrm{Cl}$ & $P$ value & HR & $95 \% \mathrm{Cl}$ & $P$ value \\
\hline Age $(\geq 60$ vs $<60)$ & 1.41 & $0.88-2.25$ & 0.159 & 1.32 & $0.81-2.15$ & 0.266 \\
\hline Gender (female vs male) & 0.89 & $0.55-1.44$ & 0.648 & 1.19 & $0.73-1.96$ & 0.489 \\
\hline Tumor location (upper vs others) & 1.06 & $0.54-2.07$ & 0.864 & 1.02 & $0.52-2.01$ & 0.960 \\
\hline Tumor size $(\geq 2 \mathrm{~cm}$ vs $<2 \mathrm{~cm})$ & 1.00 & $0.63-1.61$ & 0.987 & 0.96 & $0.59-1.54$ & 0.850 \\
\hline Depth of invasion (submucosa vs mucosa) & 1.84 & $1.15-2.94$ & 0.011 & 2.26 & $1.39-3.67$ & 0.001 \\
\hline Macroscopic type (depressed vs others) & 1.24 & $0.78-1.98$ & 0.356 & 1.36 & $0.85-2.18$ & 0.195 \\
\hline Node metastasis (yes vs no) & 3.17 & $1.92-5.21$ & $<0.001$ & 3.13 & $1.84-5.32$ & $<0.001$ \\
\hline Histology (undifferentiated vs differentiated type) & 2.90 & $1.75-4.79$ & $<0.001$ & 2.54 & $1.51-4.28$ & $<0.001$ \\
\hline H. pylori eradication (no vs yes) & 1.64 & $1.03-2.61$ & 0.037 & 1.73 & $1.08-2.77$ & 0.023 \\
\hline
\end{tabular}

H. pylori Helicobacter pylori, HR Hazard ratio, Cl Confidence interval

$P=0.023)$ as statistically significantly independent risk factors of recurrence shown in Table 2.

\section{Risk factors of overall survival among postoperative with EGC}

We also conducted univariate Cox analysis to identify the prognostic significance of clinicopathological factors for OS. Patient's age $\geq 60$ years old (HR, 3.40; $95 \%$ CI, 2.08 5.55; $P<0.001)$, positive node metastasis (HR, 3.71; $95 \%$ CI, 2.25-6.12; $P<0.001$ ), submucosal invasion (HR, 1.86; 95\% CI, 1.14-3.04; $P=0.013)$, tumor located in the upper third part (HR, 2.02; 95\% CI, 1.13-3.61; $P=0.017)$, non- $H$. pylori eradication (HR, 1.68; 95\% CI, 1.03-2.74; $P=0.036$ ), and undifferentiated type (HR, 3.06; 95\% CI, 1.79-5.23; $P<0.001)$ were risk factors for overall survival in patients with EGC. In multivariate analysis, patient's age $\geq 60$ years old (HR, 3.32; 95\% CI, 2.00-5.53; $P<0.001$ ), positive node metastasis (HR, 3.71; 95\% CI, 2.25-6.12; $P<0.001$ ), undifferentiated type (HR, 3.06; 95\% CI, 1.79-5.23; $P<0.001$ ), and non- $H$. pylori eradication (HR, 1.83; 95\% CI, 1.11-3.02; $P=0.018$ ) were found to be statistically significant independent risk factors of overall survival shown in Table 3.

\section{Prognosis and survival analysis}

Sixty-seven patients (15.6\%) died during a median followup of 69 months (range from 18 to 119 months). Threeand 5-year survival rates were separately $98.5 \%$ and $93.6 \%$ in group A and separately $96.9 \%$ and $86.6 \%$ in group B (Fig. 1A). It is obvious that the survival rate of group A was higher than that of group $\mathrm{B}$, and the difference was statistically significant (log-rank $P=0.034)$. There were 73 patients $(17.0 \%)$ with recurrence during the follow-up, 3 - and 5-year recurrence rates were separately $1.2 \%$ and $9.3 \%$ in group A, and separately $2.6 \%$ and $16.4 \%$ in group $B$ (Fig. 1B). It is shown that the recurrence rate was lower in group $A$ than in group $B(\log -\operatorname{rank} P=0.035)$.

\section{Discussion}

The occurrence of GC is a long-term process involving multiple factors. The underlying causes of $\mathrm{GC}$ are not fully understood. Since Warren and Mashall discovered $H$. pylori in 1983, the WHO concluded in 1994 that H. pylori is a carcinogen and plays a causative role in the pathogenesis of GC [8]. H. pylori-induced chronic inflammation and

Table 3 Predictive factors of overall survival of postoperative EGC

\begin{tabular}{|c|c|c|c|c|c|c|}
\hline & \multicolumn{3}{|c|}{ Univariate } & \multicolumn{3}{|c|}{ Multivariate } \\
\hline & HR & $95 \% \mathrm{Cl}$ & $P$ value & $\mathrm{HR}$ & $95 \% \mathrm{Cl}$ & $P$ value \\
\hline Age $(\geq 60$ vs $<60)$ & 3.40 & $2.08-5.55$ & $<0.001$ & 3.32 & $2.00-5.53$ & $<0.001$ \\
\hline Gender (female vs male) & 0.90 & $0.55-1.49$ & 0.689 & 1.43 & $0.84-2.44$ & 0.186 \\
\hline Tumor location (upper vs others) & 2.02 & $1.13-3.61$ & 0.017 & 1.68 & $0.92-3.07$ & 0.091 \\
\hline Tumor size ( $\geq 2 \mathrm{~cm}$ vs $<2 \mathrm{~cm}$ ) & 1.23 & $0.74-2.03$ & 0.427 & 1.22 & $0.73-2.05$ & 0.456 \\
\hline Depth of invasion (submucosa vs mucosa) & 1.86 & $1.14-3.04$ & 0.013 & 2.13 & $1.28-3.54$ & 0.004 \\
\hline Macroscopic type (depressed vs others) & 0.87 & $0.61-1.24$ & 0.450 & 1.45 & $0.88-2.39$ & 0.146 \\
\hline Node metastasis (yes vs no) & 3.71 & $2.25-6.12$ & $<0.001$ & 3.57 & $2.05-6.22$ & $<0.001$ \\
\hline Histology (undifferentiated vs differentiated type) & 3.06 & $1.79-5.23$ & $<0.001$ & 2.12 & $1.20-3.72$ & 0.009 \\
\hline H. pylori eradication (no vs yes) & 1.68 & $1.03-2.74$ & 0.036 & 1.83 & $1.11-3.02$ & 0.018 \\
\hline
\end{tabular}

H. pylori Helicobacter pylori, HR Hazard ratio, CI Confidence interval 

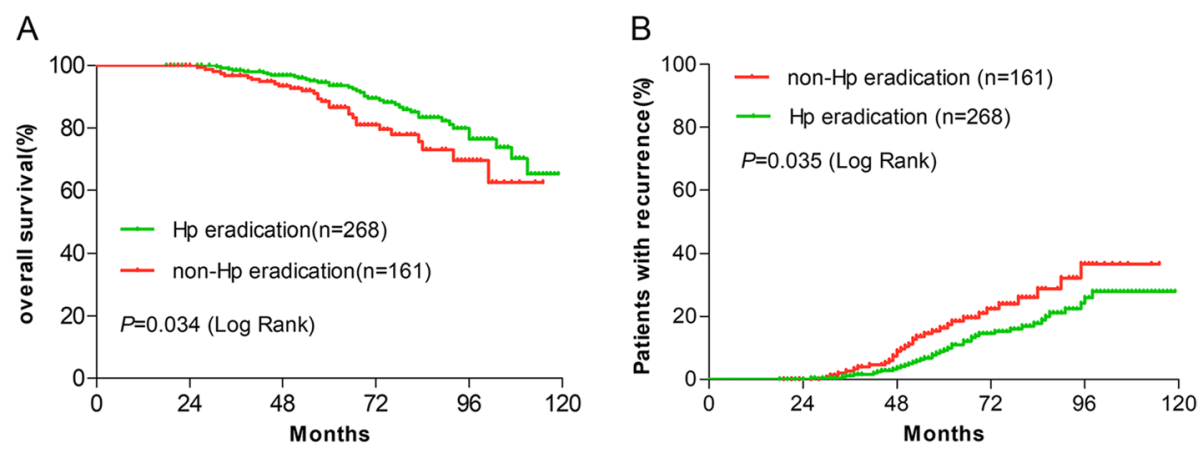

Fig. 1 Kaplan-Meier analysis of the rate of overall survival and recurrence. As shown in Fig. 1, during a median follow-up of 69 months, 38 of 268 (14.2\%) patients died in group A and 29 of 161 (18.0\%) patients died in group B (A). There were 38 of 268 (15.3\%) patients with recurrence in group A and 29 of 161 (19.9\%) patients with recurrence in group B (B)

cancerization are associated with interaction of bacteria, host, and environment which forms a complex network to respond to inflammation and promote damage repair. H. pylori eradication, used to treat functional dyspepsia and prevent peptic ulcer disease that relapses after early ulcers, was found to prevent GC in a meta-analysis, showing a $50 \%$ reduction in risk $[9,10]$. Hwang et al. found that $H$. pylori eradication may prevent intestinal-type GC by regression of atrophic gastritis and intestinal metaplasia in a prospective study for up to 10 years [11].

Although the mechanism of $H$. pylori causing $\mathrm{GC}$ has been extensively studied, few studies have been conducted on whether $H$. pylori eradication after the occurrence of $\mathrm{GC}$ can prevent the recurrence of GC and its effect on the prognosis after radical gastrectomy. For a long time, there is no international consensus on whether patients with GC can benefit from H. pylori eradication treatment. In this study, we found that the tumor located in the upper third was a risk factor for the overall survival of patients with EGC in univariate analysis, but not in multivariate analysis, and Xue et al. found that proximal gastric cancer patients had lower rates than distal gastric cancer patients in terms of 1-, 3-, and 5-year OS [12]; this may be related to the location of surgical resection and reconstruction method. We found that positive node metastasis, undifferentiated type, and non- $H$. pylori eradication were statistically significantly independent risk factors of postoperative recurrence and death in patients with EGC. However, Choi $\mathrm{J}$ et al. found that eradication of $H$ pylori after endoscopic resection of gastric tumors did not significantly reduce the incidence of metachronous gastric carcinoma in a prospective trial [13]. While Il Ju Choi et al. found that patients with EGC who received $H$. pylori treatment had lower rates of metachronous GC and more improvement from baseline in the grade of gastric corpus atrophy than patients who received placebo [14]. As for why there is such a difference, we have some speculations, firstly, the gut microbiota after gastrectomy showed higher species diversity and richness, together with greater abundance of aerobes, facultative anaerobes, and oral microbes [15]. Secondly, recent study showed that the diversity of gastric microbiota is lower in H. pylori-infected individuals than in non-H. pylori-infected individuals [16]. The diversity of gastric microbiota could be restored to a level similar to that in non- $H$. pylori-infected individuals after successful $H$. pylori eradication [17]. We speculate that the differences in gut microbiota between different populations may lead to different effects of $H$. pylori eradication on the prognosis of patients with EGC.

Our study has several limitations. Firstly, total case number may not be sufficient. Secondly, all of the patients included were from Hunan Province and may not be applicable to populations in other regions. Thirdly, this is a retrospective study, whose level of evidence is lower than that of randomized controlled trials, which may affect the reliability of the conclusions of this study.

\section{Conclusion}

In this study, $H$. pylori eradication resulted in a reduced risk of recurrence in patients with EGC after radical gastrectomy and a better prognosis than in those without $H$. pylori eradication. This study provides evidence-based information on the prophylactic effect of $H$. pylori eradication on the postoperative recurrence of EGC, which may serve as a reference for determining whether or not to eradicate $H$. pylori in patients with EGC after radical gastrectomy. In conclusion, $H$. pylori eradication treatment could prevent the recurrence of postoperative EGC to prolong the overall survival of patients with EGC.

\section{Acknowledgements \\ Not applicable.}

\section{Authors' contributions}

$\mathrm{CH}$ and SL conceived and designed the experiments. LW, JF, SL, and FB carried out the study and analyzed the data. $H L, H G, L Z$, and TX collected data. XY, AQ, and HB 
helped design the experiments. LW wrote the paper. CH checked the paper. SL performed language correction. All authors read and approved the final manuscript.

\section{Authors' information}

Chaohui Zuo, M.D, Ph.D, Professor, Director of Department of Gastroduodenal and pancreatic Surgery, Director of Laboratory of Digestive Oncology, Affiliated Tumor Hospital of Xiangya Medical School \& Hunan Province Cancer Hospital, Central South University, Vice Director of Hunan University- Hunan Province Cancer Hospital Joint Center of Liver Cancer Translational Medicine; Tongzipo Road 383, 410013 Changsha, Hunan Province, P.R.C; Tel: + 8673189762140 . He is currently investigating the clinical treatment and molecular biology of the recurrence and metastasis for digestive oncology as a researcher.

Sanlin Lei, M.D, Ph.D, Vice Professor, Department of General Surgery, The Second Xiangya Hospital of Central South University, 139 Renmin Middle Road, 410011 Changsha, Hunan Province, P.R.C; Tel: + 8673189762140. He is currently investigating the clinical treatment and molecular biology of the recurrence and metastasis for gastric cancer as a researcher.

\section{Funding}

The study was supported by the Department of Finance of Hunan Province Technology Project (2050205, to Chaohui Zuo).

\section{Availability of data and materials}

Not applicable.

\section{Declarations}

\section{Ethics approval and consent to participate}

This study was approved by the Ethics Committee of Hunan Cancer Hospital, the Second Xiangya Hospital of Central South University, the Second Affiliated Hospital of University of South China, the Central Hospital of Xiangtan City, Yongzhou Central Hospital, and the People Hospital of Qiyang County. All patients involved in this study provided informed consent for the use of their personal data for research purposes. Informed consent was obtained from all individual participants included in the study.

\section{Consent for publication}

Written informed consent for publication was obtained from all participants.

\section{Competing interests}

The authors have no conflict of interest.

\section{Author details}

${ }^{1}$ Graduates School, University of South China, 28 Zhengxiang Road, Hengyang, Hunan Province 421001, People's Republic of China. ${ }^{2}$ Department of Gastroduodenal and Pancreatic Surgery, Translational Medicine Research Center of Liver Cancer, Laboratory of Digestive Oncology, Hunan Cancer Hospital (Hunan Cancer Institute) \& the Affiliated Cancer Hospital of Xiangya School of Medicine, Hunan Province Key Laboratory of Virology (Tumor Immunity), Central South University, 283 Tongzipo Road, Changsha, Hunan Province 410013, People's Republic of China. ${ }^{3}$ Cancer Research Institute, Department of Gastrointestinal Surgery of Second Affiliated Hospital, University of South China, 28 Zhengxiang Road, Hengyang, Hunan Province 421001, People's Republic of China. ${ }^{4}$ The Third Department of General Surgery, The Central Hospital of Xiangtan City, 120 Heping Road, Xiangtan City, Hunan Province 411100, People's Republic of China. ${ }^{5}$ Department of General Surgery, Yongzhou Central Hospital, Xiaoshui Road, Yongzhou City, Hunan Province 425000, People's Republic of China. ${ }^{6}$ Department of General Surgery, People Hospital of Qiyang County, Xiaoshui Road, Qiyang County, Hunan Province 426100, People's Republic of China. ${ }^{7}$ Department of General Surgery, The Second Xiangya Hospital of Central South University, 139 Renmin Middle Road, Changsha, Hunan Province 410011, People's Republic of China.

Received: 8 February 2021 Accepted: 23 July 2021

Published online: 21 September 2021

\section{References}

1. Bray F, Ferlay J, Soerjomataram I, Siegel RL, Torre LA, Jemal A. Global cancer statistics 2018: GLOBOCAN estimates of incidence and mortality worldwide for 36 cancers in 185 countries. CA Cancer J Clin. 2018;68(6):394-424. https://doi.org/10.3322/caac.21492.

2. Craanen ME, Dekker W, Blok P, Ferwerda J, Tytgat GN. Intestinal metaplasia and Helicobacter pylori: an endoscopic bioptic study of the gastric antrum. Gut. 1992;33(1):16-20. https://doi.org/10.1136/gut.33.1.16.

3. Parsonnet J, Friedman GD, Vandersteen DP, Chang Y, Vogelman JH, Orentreich N, Sibley RK. Helicobacter pylori infection and the risk of gastric carcinoma. N Engl J Med. 1991;325(16):1127-31. https://doi.org/10.1056/ NEJM199110173251603.

4. Helicobacter and Cancer Collaborative Group. Gastric cancer and Helicobacter pylori: a combined analysis of 12 case control studies nested within prospective cohorts. Gut. 2001;49(3):347-53. https://doi.org/10.1136/gut.49.3.347.

5. Allemani C, Weir HK, Carreira H, Harewood R, Spika D, Wang XS, Bannon F, Ahn JV, Johnson CJ, Bonaventure A, Marcos-Gragera R, Stiller C, Azevedo e Silva G, Chen WQ, Ogunbiyi OJ, Rachet B, Soeberg MJ, You H, Matsuda T, Bielska-Lasota M, Storm H, Tucker TC, Coleman MP, CONCORD Working Group. Global surveillance of cancer survival 1995-2009: analysis of individual data for 25,676,887 patients from 279 population-based registries in 67 countries (CONCORD-2). Lancet. 2015;385(9972):977-1010. https://doi. org/10.1016/S0140-6736(14)62038-9.

6. Lee YC, Chiang TH, Chou CK, Tu YK, Liao WC, Wu MS, Graham DY. Association between Helicobacter pylori eradication and gastric cancer incidence: a systematic review and meta-analysis. Gastroenterology. 2016;150(5):11131124.e5. https://doi.org/10.1053/j.gastro.2016.01.028.

7. Japanese Gastric Cancer Association. Japanese classification of gastric carcinoma: 3rd English edition. Gastric Cancer. 2011;14(2):101-12. https:// doi.org/10.1007/s10120-011-0041-5.

8. Tsukamoto T, Nakagawa M, Kiriyama Y, Toyoda T, Cao X. Prevention of gastric cancer: eradication of Helicobacter pylori and beyond. Int J Mol Sci. 2017;18(8):1699. https://doi.org/10.3390/ijms18081699.

9. Doorakkers E, Lagergren J, Engstrand L, Brusselaers N. Eradication of Helicobacter pylori and gastric cancer: a systematic review and meta-analysis of cohort studies. J Natl Cancer Inst. 2016;108(9):132. https://doi.org/10.1093/jnci/djw132.

10. Ford AC, Forman D, Hunt RH, Yuan Y, Moayyedi P. Helicobacter pylori eradication therapy to prevent gastric cancer in healthy asymptomatic infected individuals: systematic review and meta-analysis of randomised controlled trials. BMJ (Clinical research ed). 2014;348: g3174. https://doi.org/10.1136/ bmj.g3174.

11. Hwang YJ, Kim N, Lee HS, Lee JB, Choi YJ, Yoon H, Shin CM, Park YS, Lee DH. Reversibility of atrophic gastritis and intestinal metaplasia after Helicobacter pylori eradication - a prospective study for up to 10 years. Aliment Pharmacol Ther. 2018;47(3):380-90. https://doi.org/10.1111/apt.14424.

12. Xue J, Yang $H$, Huang $S$, et al. Comparison of the overall survival of proximal and distal gastric cancer after gastrectomy: a systematic review and meta-analysis. World J Surg Onc. 2021;19:17. https://doi.org/10.1186/s12957-021-02126-4.

13. Choi J, Kim SG, Yoon H, Im JP, Kim JS, Kim WH, Jung HC. Eradication of Helicobacter pylori after endoscopic resection of gastric tumors does not reduce incidence of metachronous gastric carcinoma. Clin Gastroenterol Hepatol. 2014;12(5):793-800.e1. https://doi.org/10.1016/j.cgh.2013.09.057.

14. Choi IJ, Kook MC, Kim YI, Cho SJ, Lee JY, Kim CG, Park B, Nam BH. Helicobacter pylori therapy for the prevention of metachronous gastric cancer. N Engl J Med. 2018;378(12):1085-95. https://doi.org/10.1056/NEJMoa1708423.

15. Erawijantari PP, Mizutani S, Shiroma H, Shiba S, Nakajima T, Sakamoto T, Saito Y, Fukuda S, Yachida S, Yamada T. Influence of gastrectomy for gastric cancer treatment on faecal microbiome and metabolome profiles. Gut. 2020;69(8):1404-15. https://doi.org/10.1136/gutjnl-2019-319188.

16. Vasapolli R, Schütte K, Schulz C, Vital M, Schomburg D, Pieper DH, VilchezVargas R, Malfertheiner P. Analysis of transcriptionally active bacteria throughout the gastrointestinal tract of healthy individuals. Gastroenterology. 2019;157(4):1081-1092.e3. https://doi.org/10.1053/j.gastro.2019.05.068.

17. Guo Y, Zhang Y, Gerhard M, Gao J, Mejias-Luque R, Zhang L, Vieth M, Ma JL, Bajbouj M, Suchanek S, Liu WD, Ulm K, Quante M, Li ZX, Zhou T, Schmid R, Classen M, LiWQ, You WC, Pan KF. Effect of Helicobacter pylori on gastrointestinal microbiota: a population-based study in Linqu, a high-risk area of gastric cancer. Gut. 2020;69(9):1598-607. https://doi.org/10.1136/gutjnl-2019-319696. 
Publisher's Note

Springer Nature remains neutral with regard to jurisdictional claims in published maps and institutional affiliations.
Ready to submit your research? Choose BMC and benefit from:

- fast, convenient online submission

- thorough peer review by experienced researchers in your field

- rapid publication on acceptance

- support for research data, including large and complex data types

- gold Open Access which fosters wider collaboration and increased citations

- maximum visibility for your research: over $100 \mathrm{M}$ website views per year

At BMC, research is always in progress.

Learn more biomedcentral.com/submissions 